Article

\title{
Preparation and Characterization of Quaternized Chitosan Coated Alginate Microspheres for Blue Dextran Delivery
}

\author{
Kuo-Yu Chen * and Si-Ying Zeng \\ Department of Chemical and Materials Engineering, National Yunlin University of Science and Technology, \\ Yunlin 64002, Taiwan; M10515035@yuntech.edu.tw \\ * Correspondence: chenkuo@yuntech.edu.tw; Tel.: +886-5-534-2601 (ext. 4614); Fax: +886-5-531-2071 \\ Academic Editors: Chih-Feng Huang, Jinlian Hu and Rui Xiao \\ Received: 1 May 2017; Accepted: 5 June 2017; Published: 7 June 2017
}

\begin{abstract}
In this study, 2-[(Acryloyloxy)ethyl]trimethylammonium chloride was graft polymerized onto chitosan (CS) to form quaternary ammonium CS (QAC) by using ammonium persulfate as a redox initiator. Alginate (ALG) microspheres loaded with a water-soluble macromolecular model drug, blue dextran (BD), were obtained by corporation of coaxial gas-flow method and ionic gelation process. CS and QAC were then coated on the surfaces of ALG microspheres to generate core/shell structured CS/ALG and QAC/ALG microspheres, respectively. The experiment result showed that QAC/ALG microspheres had a smaller particle size due to the stronger electrostatic interactions between QAC and ALG molecules. In vitro drug release studies at $\mathrm{pH} 7.4$ and $\mathrm{pH} 9.0$ exhibited that the release rate of BD was significantly decreased after ALG microspheres coating with CS and QAC. Moreover, ALG microspheres coated with QAC showed a prolonged release profile for BD at $\mathrm{pH}$ 9.0. Therefore, QAC/ALG microspheres may be a promising hydrophilic macromolecular drug carrier for a prolonged and sustained delivery.
\end{abstract}

Keywords: alginate; quaternary ammonium chitosan; graft polymerized; microspheres; drug release

\section{Introduction}

Much attention has been given to stimuli-sensitive hydrogels for pharmaceutical and medical applications, such as controlled-release carriers for drug [1,2], protein [3], and vaccine [4] delivery and as scaffolds for tissue engineering [5,6]. Hydrogels could be designed to respond to external stimuli, such as $\mathrm{pH}$ and temperature [7]. The $\mathrm{pH}$ sensitive hydrogels with ionizable groups have been extensively investigated for drug delivery systems. The drug release rates of polyelectrolyte hydrogels strongly depend on the $\mathrm{pH}$ of medium and ionic strength [8]. Alginate (ALG), a natural anionic polysaccharide derived from marine brown algae, has attracted a wide range of biomedical applications because of their low cost, biocompatibility and biodegradability [9]. ALG microspheres prepared by cross-linking with calcium ions to form stable network have been widely used as carriers for the controlled release of drugs and active agents [10,11].

Chitosan (CS), another natural derived polysaccharide, is a biodegradable, non-toxic and biocompatible polymer that has been widely applied in drug delivery systems. In acidic media $(\mathrm{pH}<6.5)$, CS becomes a cationic polymer due to protonation, which could form polyelectrolyte with negatively charged ALG by electrostatic interactions. Coating of ALG microspheres with CS layer could prolong drug release in physiological environment compared with ALG microspheres $[3,12]$ However; changes in the $\mathrm{pH}$ of the environment can influence the degree of ionization of $\mathrm{CS}$, resulting in increased or decreased electrostatic interactions between CS and ALG. 
Previous study indicated that the quaternized CS increased positive charge density and enhanced solubility in neutral and basic environments [13]. The positive charge characteristic of quaternary ammonium cation is independent of the $\mathrm{pH}$ of the aqueous medium [14]. Furthermore, ALG beads coated with quaternized CS containing a higher degree of substitution significantly decreased the release of brilliant blue in $0.9 \%(w / v) \mathrm{NaCl}$ [15]. However, a high burst release of around $30 \%$ was still discovered in $2 \mathrm{~h}$ when quaternized CS had the highest degree of substitution (95\%). The molecular structure of CS will affect its binding with ALG. These quaternary ammonium groups of quaternized CS were very close to the CS backbone. Interaction between the quaternary ammonium groups of quaternized CS and carboxylate groups of ALG may be lessened due to steric repulsions between the two molecules. It is interesting to prepare quaternized CS with long pendant side-chains and large charge density by graft copolymerization, which could reduce the intermolecular and intramolecular hydrogen bonds of CS and increase the water solubility of CS. The flexible side-chains with plenty of quaternary ammonium cations on the rigid CS backbone was expected to extend in a plurality of directions and interact with various different ALG molecules through electrostatic interactions, resulting in a highly cross-linked layer. Moreover, the positive charge characteristic of quaternary ammonium cations is independent of the $\mathrm{pH}$ of their surrounding medium. The amino $\left(-\mathrm{NH}_{2}\right)$ and hydroxyl $(-\mathrm{OH})$ groups present on the CS backbone can be grafted. The grafting copolymerization of CS with a variety of cationic monomers using redox initiators has been reported in literature [16]. To the best of our knowledge, however, there has been no report on ALG microspheres coated with cationic graft copolymer of CS, and its use as a drug carrier.

Blue dextran (BD) is a stable, high-molecular-weight and water-soluble dextran with covalently bonded blue dye [17]. BD was chosen as a water-soluble biomacromolecular drug model because of its ease of analysis by UV-vis spectrometry [10,18].

In this study, a cationic graft copolymer (QAC) of CS graft-polymerized with quaternary ammonium-containing monomers was synthesized. ALG microspheres were prepared by corporation of coaxial gas-flow technique and ionic gelation process. Then, ALG microspheres were coated with CS and QAC to fabricate CS/ALG and QAC/ALG microspheres, respectively. To investigate the in vitro drug release behavior, $\mathrm{BD}$ was used as a high-molecular-weight and hydrophilic model drug to discuss the controlled release of ALG, CS/ALG and QAC/ALG microspheres in different $\mathrm{pH}$ medium.

\section{Materials and Methods}

\subsection{Materials}

Sodium alginate was obtained from Acros Organics (Geel, Belgium). CS with molecular weight of 50-190 kDa and deacetylated degree of 75-85\% was purchased from Sigma-Aldrich (St. Louis, MO, USA). 2-[(Acryloyloxy)ethyl]trimethylammonium chloride (AETMAC, $80 \mathrm{wt} \%$ in water) and blue dextran with molecular weight of $2000 \mathrm{kDa}$ were also obtained from Sigma-Aldrich. Ammonium persulfate was supplied from Showa Chemicals (Tokyo, Japan). Calcium chloride $\left(\mathrm{CaCl}_{2}\right)$, acetic acid, hydrochloric acid $(\mathrm{HCl})$ and sodium hydroxide $(\mathrm{NaOH})$ were obtained from Katayama Chemical (Osaka, Japan). Acetone and methanol were bought from Echo Chemical (Miaoli, Taiwan). Phosphate buffer solution was from UniRegion Bio-Tech (Hsinchu, Taiwan). All reagents were used as received with no additional purification. Aqueous solutions were prepared using deionized water.

\subsection{Synthesis of Quaternary Ammonium CS (QAC)}

QAC was synthesized by the graft polymerization of a cationic monomer, AETMAC, onto CS in aqueous acetic acid with a redox initiator system of ammonium persulfate. Briefly, a $1 \%(w / v)$ acid aqueous solution of CS was prepared by dissolving CS powder in $2 \%(v / v)$ aqueous acetic acid at $80^{\circ} \mathrm{C}$ in a four-neck flask equipped with a mechanical stirrer, condenser, nitrogen inlet and addition funnel. The CS solution was purged with nitrogen for $30 \mathrm{~min}$. Then, $0.015 \mathrm{M}$ AETMAC and $0.015 \mathrm{M}$ ammonium sulfate were added successively dropwise to initiate graft polymerization under 
nitrogen atmosphere. After reaction for $3 \mathrm{~h}$ at $80^{\circ} \mathrm{C}$, the reaction mixture was cooled down to room temperature and poured into excess of acetone. The precipitate was filtered off, washed with methanol to remove unreacted AETMAC monomer and poly[2-(acryloyloxy)ethyl]trimethylammonium chloride (PAETMAC) homopolymer. Finally, the resultant product was dried in a drying oven.

\subsection{Preparation of $B D$-Loaded $A L G, C S / A L G$ and $Q A C / A L G$ Microspheres}

ALG loaded with hydrophilic model drug, BD, were obtained by using a coaxial nitrogen flow encapsulator and ionic gelation method $[19,20]$. CS and QAC were then coated on the surfaces of ALG to generate core/shell structured, respectively. Briefly, a 1.2\% $(w / v)$ aqueous solution of ALG was prepared by dissolving sodium alginate in deionized water. BD was then added into the ALG solution and mixed homogeneously with a magnetic stirrer. The weight ratio of BD to ALG was 1:10. BD-loaded ALG solution was injected through a needle with an inner gauge diameter of $0.17 \mathrm{~mm}$ into $5 \%(w / v)$ aqueous $\mathrm{CaCl}_{2}$ solution. The particle size of microspheres was controlled by regulating the extrusion flow rate using a syringe pump (KDS-100, KD Scientific, Holliston, MA, USA) at a flow rate of $5 \mathrm{~mL} / \mathrm{h}$ and by applying a coaxial nitrogen flow using a Var J1 encapsulation unit (Nisco, Zurich, Switzerland) at a rate of $4 \mathrm{~L} / \mathrm{min}$. The obtained microspheres were incubated in in the $\mathrm{CaCl}_{2}$ solution for $30 \mathrm{~min}$ at room temperature to completely cross-link, and were washed gently with deionized water for two times to remove $\mathrm{BD}$ attached on the microsphere surface.

CS and QAC were dissolved in $1 \%(w / v)$ aqueous acetic acid solution to prepare $0.5 \%(w / v)$ $\mathrm{CS}$ and QAC solutions, respectively. The $\mathrm{pH}$ of CS and QAC solutions was adjusted to 6.3 with $1 \mathrm{~N}$ $\mathrm{NaOH}$ solution. BD-loaded ALG microspheres were then added drop-wise into CS and QAC solutions, stirred for $30 \mathrm{~min}$ and washed with deionized water to produce BD-loaded CS/ALG and QAC/ALG microspheres, respectively. The theoretical weight ratio of CS/ALG or QAC/ALG was fixed at 1:1. The actual weight ratio of CS/ALG or QAC/ALG was calculated as: $\left(W_{\mathrm{d}}-W_{\mathrm{s}}\right) / W_{\mathrm{s}}$, where $W_{\mathrm{d}}$ is the dry weight of BD-loaded CS/ALG or BD-loaded QAC/ALG microspheres and $W_{\mathrm{s}}$ is the dry weight of BD-loaded ALG microspheres.

\subsection{Characterizations}

Proton nuclear magnetic resonance $\left({ }^{1} \mathrm{H}\right.$ NMR) spectra were collected on an Agilent Technologies DD2 NMR spectrometer (Santa Clara, CA, USA) operating at $600 \mathrm{MHz}$. CS and QAC samples were dissolved in $1 \%(v / v)$ CD3COOD in $\mathrm{D}_{2} \mathrm{O}$ before NMR test. The $\mathrm{D}_{2} \mathrm{O}$ peak was used as a reference peak. Infrared survey spectra of dry CS and QAC within the range $4000-500 \mathrm{~cm}^{-1}$ were recorded on a Fourier transform infrared spectrophotometer (FTIR; Bio-Rad FTS-40, Hercules, CA, USA) operated with a dry air purge. The dry sample was mixed with $\mathrm{KBr}$ and compressed into thin disks. The spectra were collected at resolution of $2 \mathrm{~cm}^{-1}$ and by averaging 32 scans.

The cationic degree (CD) of QAC was determined by the precipitation titration, which depended on the amount of AETMAC units incorporated into the copolymer [21]. Briefly, $0.04 \mathrm{~g}$ of dry QAC was dissolved in $50 \mathrm{~mL}$ of deionized water, and $1 \mathrm{~mL}(5 \%(w / v))$ of aqueous potassium chromate was added as indicator. The solution was titrated with $0.01 \mathrm{M}$ aqueous silver nitrate. The endpoint of titration was reached until the color changed to brick red. The CD of QAC was calculated as follows: $\mathrm{CD}(\%)=\left\{\left[193.67 \times c \times\left(\mathrm{V}-V_{0}\right)\right] /(1000 \times W)\right\} \times 100 \%$, where $c(\mathrm{~mol} / \mathrm{L})$ is the concentration of aqueous silver nitrate; $V(\mathrm{~mL})$ and $V_{0}(\mathrm{~mL})$ are the volumes of the consumed aqueous silver nitrate for titration of QAC and the blank, respectively; $W(\mathrm{~g})$ is the weight of QAC; and 193.67 (mol/g) is the molecular weight of AETMAC.

Wide-angle X-ray diffraction (WAXD) measurements were performed on CS and QAC using a Rigaku MiniflexII X-ray diffractometer (Tokyo, Japan) equipped with $\mathrm{Cu}-\mathrm{K} \alpha$ radiation over a range (20) of $2^{\circ}-50^{\circ}$, at a scan rate of $2^{\circ} \mathrm{min}^{-1}$.

Furthermore, the shape of prepared microspheres was examined under an optical microscopy (M835, Microtech; Eugene, OR, USA) equipped with a CCD camera. The average diameter of 
microspheres was measured from several optical microscopy images and using image analysis software MICROCAM (M\&T Optics, Taipei, Taiwan).

\subsection{In Vitro Drug Release}

\subsubsection{Drug Encapsulation Efficiency}

The drug encapsulation efficiency (EE) of the microspheres was evaluated according to the method reported in previous literature [10]. The actual BD loading amount was calculated indirectly by the difference between the initial amount of BD dissolved in ALG solution and the BD released into the gelling medium and washing solutions. The absorbance of the clear supernatant was measured using a visible spectrophotometer (SP-830 Plus, Metertech, Taipei, Taiwan) at $620 \mathrm{~nm}$. The amount of BD without encapsulation was obtained by comparison with a BD calibration curve. The EE was calculated using the formula, EE $\left.(\%)=\left[\left(W_{0}-W_{\mathrm{a}}\right) / W_{0}\right)\right] \times 100 \%$, where $W_{0}$ is the initial amount of BD dissolved in ALG solution and $W_{\mathrm{a}}$ is the amount of BD lost in the gelling medium and washing solutions. The experiments were performed in triplicate and average values were taken.

\subsubsection{Cumulative Drug Release}

In vitro BD release studies were conducted in three different $\mathrm{pH}$ solutions: aqueous $\mathrm{HCl}$ solution of $\mathrm{pH} 3.0$ and PBS of $\mathrm{pH} 7.4$ and 9.0. All release experiments were performed using a shaking bath with a shaking speed of $120 \mathrm{rpm}$ at $37^{\circ} \mathrm{C}$ to maintain the microspheres in suspension. The freshly prepared microspheres were dispersed in $40 \mathrm{~mL}$ of release media. At predetermined time intervals, $4 \mathrm{~mL}$ of sample solution was withdrawn and replaced with an equal volume of fresh solution immediately. The sample solution was centrifuged at $8000 \mathrm{rpm}$ for $1 \mathrm{~min}$. The amount of released BD in the supernatant was determined as described above. The cumulative drug release (CDR, \%) of each sample was calculated according to the formula CDR $(\%)=\left(W_{t} / W_{\infty}\right) \times 100 \%$, where $W_{t}$ is the cumulative amount of BD released from the microspheres at a given time $t$ and $W_{\infty}$ is the amount of $\mathrm{BD}$ initially loaded in the microspheres. All drug release experiments were performed in triplicate and average values were taken.

\subsection{Statistical Analysis}

All quantitative data were expressed as mean \pm standard deviation. Statistical analysis was conducted using Student's $t$-test or one-way analysis of variance (ANOVA), followed by post hoc Fisher's LSD multiple comparison test. Levels of statistical significance were set at $p<0.05$.

\section{Results and Discussion}

\subsection{QAC Characteristics}

CS is used in multiple biomedical and pharmaceutical applications. However, it is not dissolved in neutral and alkali aqueous solution due to the strong intermolecular and intramolecular hydrogen-bond interactions. The graft polymerization of cationic monomers on CS chains was performed to increase solubility of $\mathrm{CS}$ in neutral and alkaline $\mathrm{pH}$ solution.

CS has two types of reactive groups, $\mathrm{C} 2-\mathrm{NH}_{2}$ and $\mathrm{C} 6-\mathrm{OH}$, which can be modified by grafting polymerization method using a redox initiator system [22,23]. The ammonium persulfate could generate the activated radical in the backbone of CS and initiate the reaction [24,25]. Then, the double bond of the AETMAC monomer was polymerized to form the grafted copolymer QAC (Figure 1). 


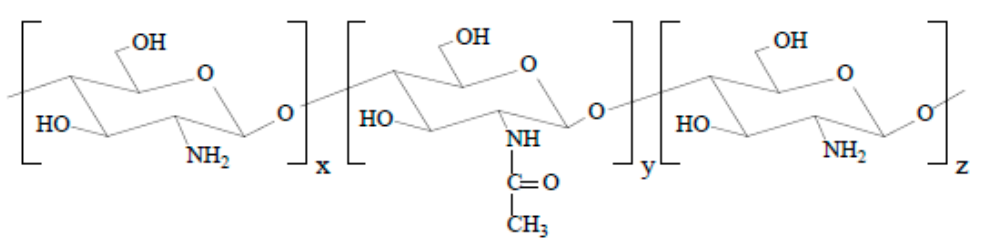

CS
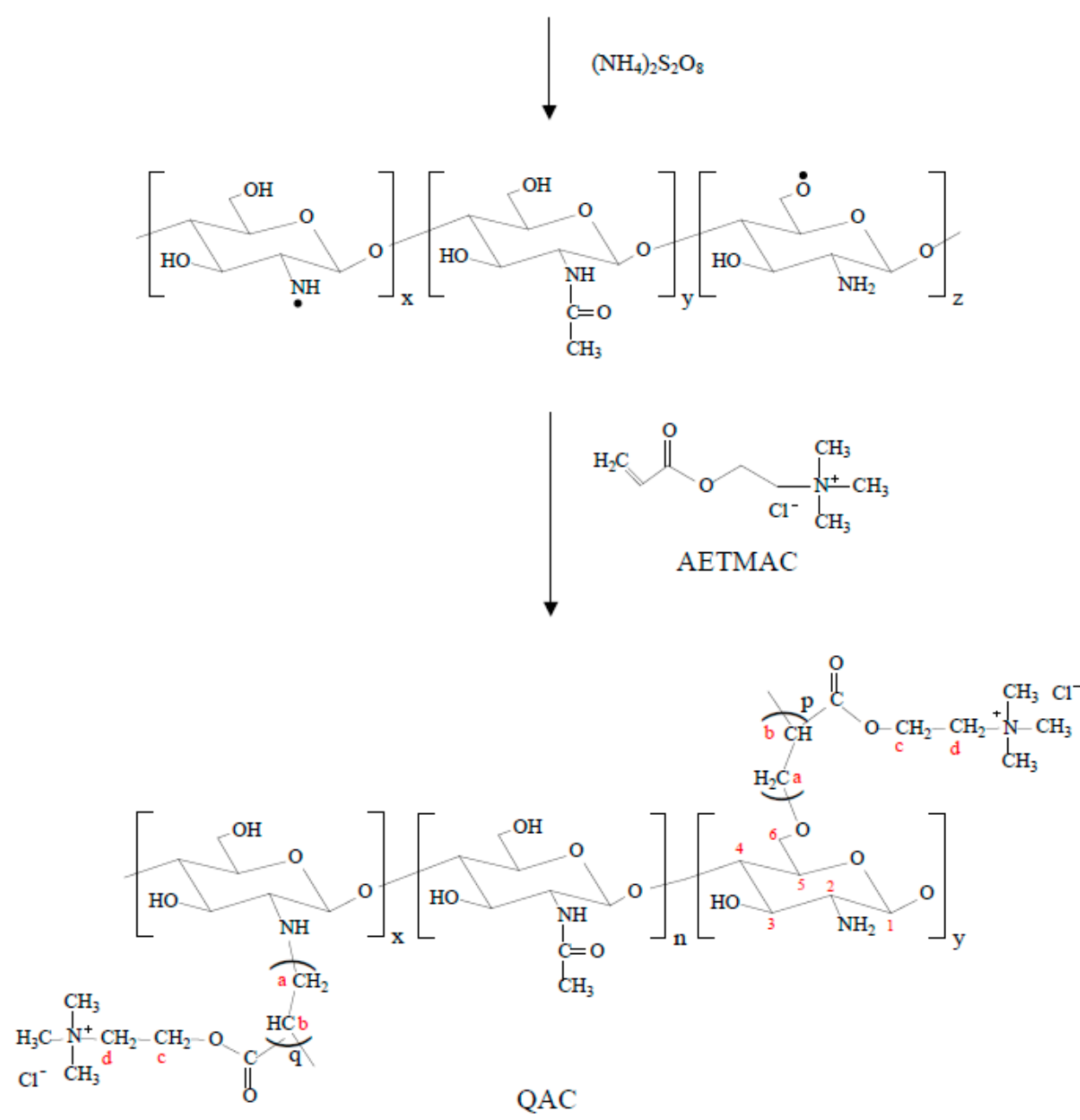

Figure 1. Schematic representation of graft-copolymerization of AETMAC onto CS.

The chemical compositions and structures of QAC were characterized by NMR, FTIR and WAXD measurements. Figure 2 displays the ${ }^{1} \mathrm{H}$ NMR spectra of CS and QAC. The sharp peak appearing at $4.85 \mathrm{ppm}$ is for water. The peaks observed at 4.6, 3.4-4.0, 3.2 and $2.05 \mathrm{ppm}$ correspond to H1, H3,4,5,6, $\mathrm{H} 2$ and $\mathrm{N}$-acetyl of CS, respectively $[21,26]$. Compared with CS, the signal observed at 3.18 ppm could be attributed to the nine protons of the quaternary ammonium group, $-\mathrm{N}^{+}\left(\mathrm{CH}_{3}\right)_{3}$, in PAETMAC $[27,28]$. Additionally, the signal at $3.0 \mathrm{ppm}$ is ascribed to methine proton ( $\mathrm{Hb}$ in Figures 1 and 2). The methylene (Ha,c,d in Figures 1 and 2) signals are also observed in QAC. Therefore, the NMR spectrum indicates that CS has grafted with AETMAC. 

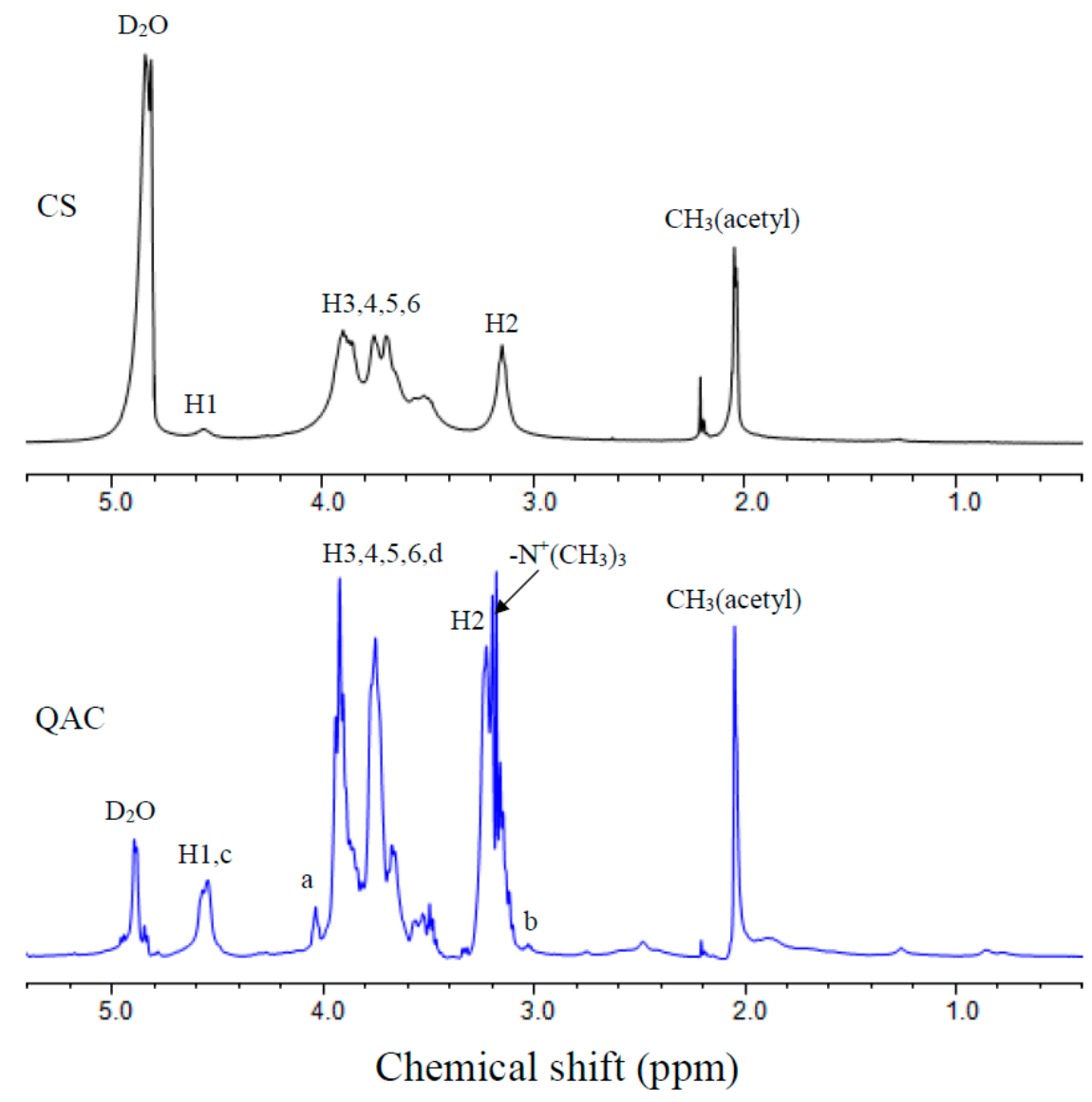

Figure 2. ${ }^{1} \mathrm{H}$ NMR spectra of CS and QAC.

The FTIR transmittance spectra of CS and QAC are shown in Figure 3. CS and QAC show a characteristic strong and broad band at $3200-3600 \mathrm{~cm}^{-1}$ for the $\mathrm{O}-\mathrm{H}$ and $\mathrm{N}-\mathrm{H}$ stretching vibrations of amino and hydroxyl groups on the backbone of CS chains. The peak at around $1645 \mathrm{~cm}^{-1}$ is ascribed to the $\mathrm{C}=\mathrm{O}$ stretching vibration of amide I groups. The band at around $1560 \mathrm{~cm}^{-1}$ is assigned to the $\mathrm{N}-\mathrm{H}$ bending and $\mathrm{C}-\mathrm{N}$ stretching vibration of amide II. In addition to the above-observed bands, QAC shows two additional characteristic absorption bands at 1733 and $952 \mathrm{~cm}^{-1}$, which could be resulted from the $\mathrm{C}=\mathrm{O}$ stretching vibration of ester groups and the $\mathrm{C}-\mathrm{N}$ stretching vibration of quaternary ammonium groups in PAETMAC, indicating the formation of graft copolymer [16,29]. Moreover, the cationic degree of QAC determined from the precipitation titration analysis is about $21.2 \%(w / w)$, which means that $0.212 \mathrm{~g}$ of PAETMAC had been grafted onto per gram of QAC.

The crystalline properties of CS and QAC were evaluated by WAXD. As shown in Figure 4, CS has two characteristic diffractive peaks at around $10.3^{\circ}$ and $20.2^{\circ}$ corresponding to the crystal forms I and II, respectively [30]. However, the intensity of these peaks for QAC sharply decreases and it becomes amorphous. This is attributed to the steric hindrance of the grafted chains: PAETMAC, obstructs the formation of intermolecular and intramolecular hydrogen bonds of the CS backbone, resulting in the disappearance of crystallinity. Therefore, the water solubility of CS would be increased via grafting of PAETMAC on CS chains [31]. 


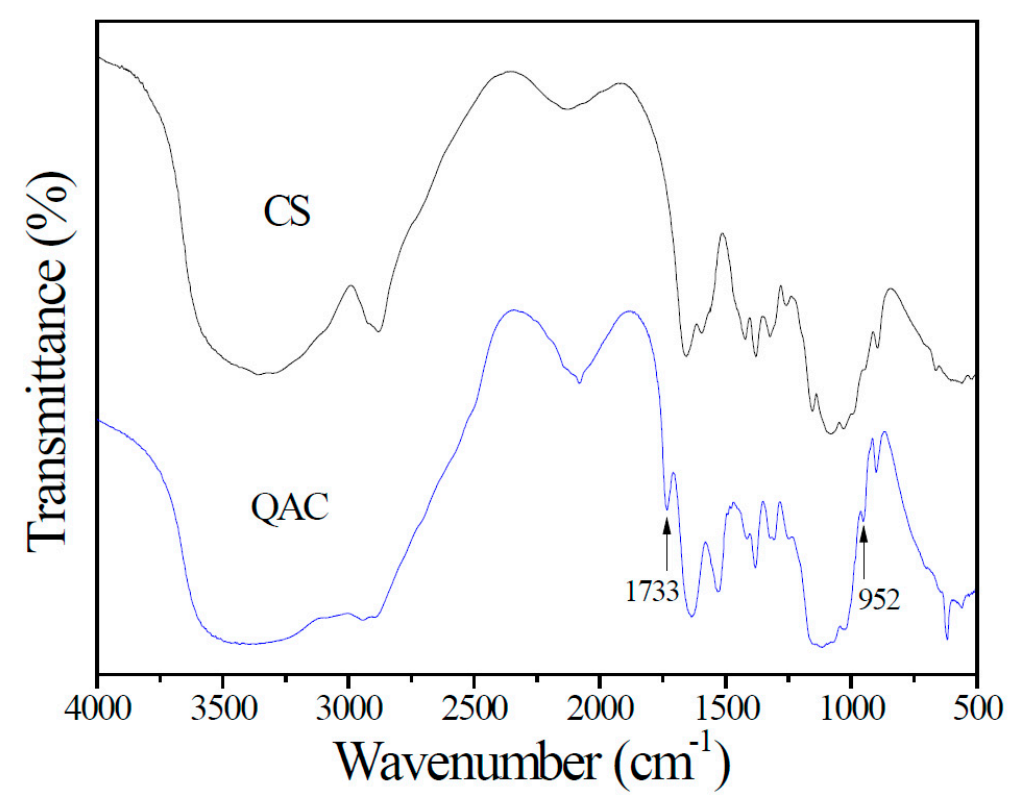

Figure 3. FTIR spectra of CS and QAC.

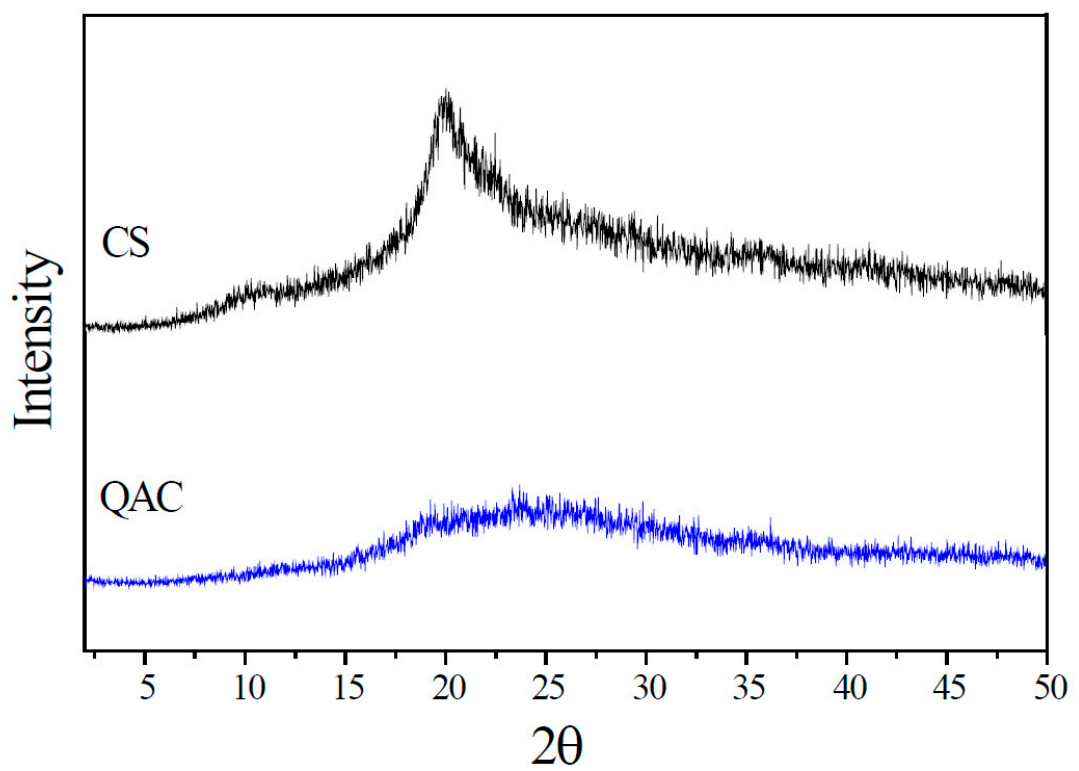

Figure 4. WAXD spectra of CS and QAC.

On the basis of NMR, FTIR and WAXD analyses, it can be concluded that AETMAC monomers have been successfully grafted onto CS.

\subsection{Microspheres Characteristics}

In this study, the weight ratio of CS to ALG or QAC to ALG was fixed at 1:1 for the preparation of microspheres. However, the actual weight ratios of CS to ALG and QAC to ALG were 0.06:1 and 0.54:1, respectively. Compared to CS, more amount of QAC was coated onto the surface of negatively charged ALG microspheres because QAC had more positive charges than CS at $\mathrm{pH}=6.3$.

Optical microphotographs of wet microspheres and their shape are shown in Figure 5. The ALG microspheres were successfully prepared via the coaxial nitrogen flow technique and ionic gelation method, resulting in a narrow size distribution. As illustrated in Figure 5, all the microspheres 
had a regular spherical shape and smooth surface. No aggregation was observed. The average diameters of ALG, CS/ALG and QAC/ALG microspheres were $212.9 \pm 8.1,317.5 \pm 10.0$ and $204.7 \pm 7.3 \mu \mathrm{m}$, respectively. The coating of CS on ALG microspheres result caused an increase in mean diameter to around $105 \mu \mathrm{m}$. However, ALG microspheres coated with QCA led to a decrease in the mean diameter $(p<0.05)$. Although, compared to CS, more amount of QCA was coated onto ALG microspheres, QAC/ALG microsphere had a significantly smaller particle size than CS/ALG microspheres. The difference in the particle size of the microspheres could be due to the difference in the electrostatic interactions occurring between the coating layer and ALG microspheres. QAC has a higher positive charge density than CS at neutral environment, resulting in a stronger electrostatic interaction with ALG. Therefore, QAC/ALG microsphere has the smallest particle size.
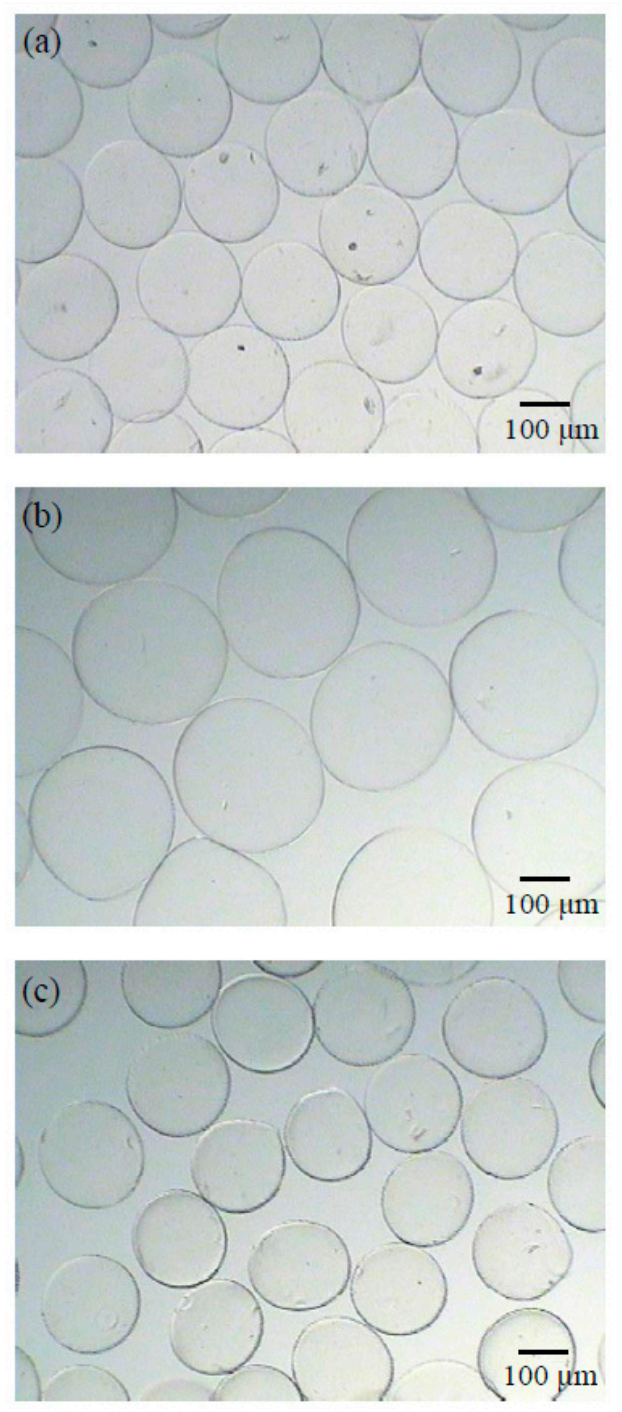

Figure 5. Optical microphotographs of: (a) ALG; (b) CS/ALG; and (c) QAC/ALG microspheres after soaking in deionized water.

\subsection{BD Release Prolife}

ALG microspheres was coated with polycations to decrease the degree of drug burst release from microspheres but minimal effects on drug encapsulation efficiency were desirable. The drug encapsulation efficiency of the ALG, CS/ALG and QAC/ALG microsphere was $54.4 \% \pm 1.5 \%, 52.4 \% \pm$ $5.6 \%$ and $54.6 \% \pm 3.8 \%$, respectively. There were no significant differences in encapsulation efficiency 
among the different microspheres $(p>0.05)$. The result indicates that the coating process of CS and QAC on ALG microspheres had no detrimental effect on the drug encapsulation efficiency.

The BD release behavior from different microspheres was studied in aqueous $\mathrm{HCl}$ solution (at $\mathrm{pH}=3.0$ ) and $\mathrm{PBS}$ (at $\mathrm{pH}=7.4$ and 9.0). The release profiles of $\mathrm{BD}$ from the prepared microspheres are presented in Figure 6. Figure 6a shows the percentage of cumulative BD release at $37^{\circ} \mathrm{C}$ from the ALG, CS/ALG and QAC/ALG microspheres in aqueous $\mathrm{HCl}$ solution of $\mathrm{pH} 3.0$. About $17 \%$ and $11 \%$ of total amount of BD were released in seven days from ALG and QAC/ALG microsphere, respectively, and slow release after the initial release was continued. It was clear that the BD release rate of ALG microspheres was much higher than that of QAC/ALG microspheres. The difference in the release rate between ALG and QAC/ALG microspheres become more distinguishable with increasing time. The percentage of cumulative BD release reached 33\% for ALG microspheres, whereas the value was only $21 \%$ for QAC/ALG microspheres within 63 days. The result suggested that QAC microspheres coating effectively decreased the release of $\mathrm{BD}$ in acid environment. In contrast, very low amount $(<1 \%)$ of BD was released from CS/ALG microspheres during the first 21 days. After 28 days, they started to release rapidly BD up to $32 \%$ in 63 days. After 49 days, the amount of BD released from CS/ALG microspheres was higher than that from QAC/ALG microspheres.
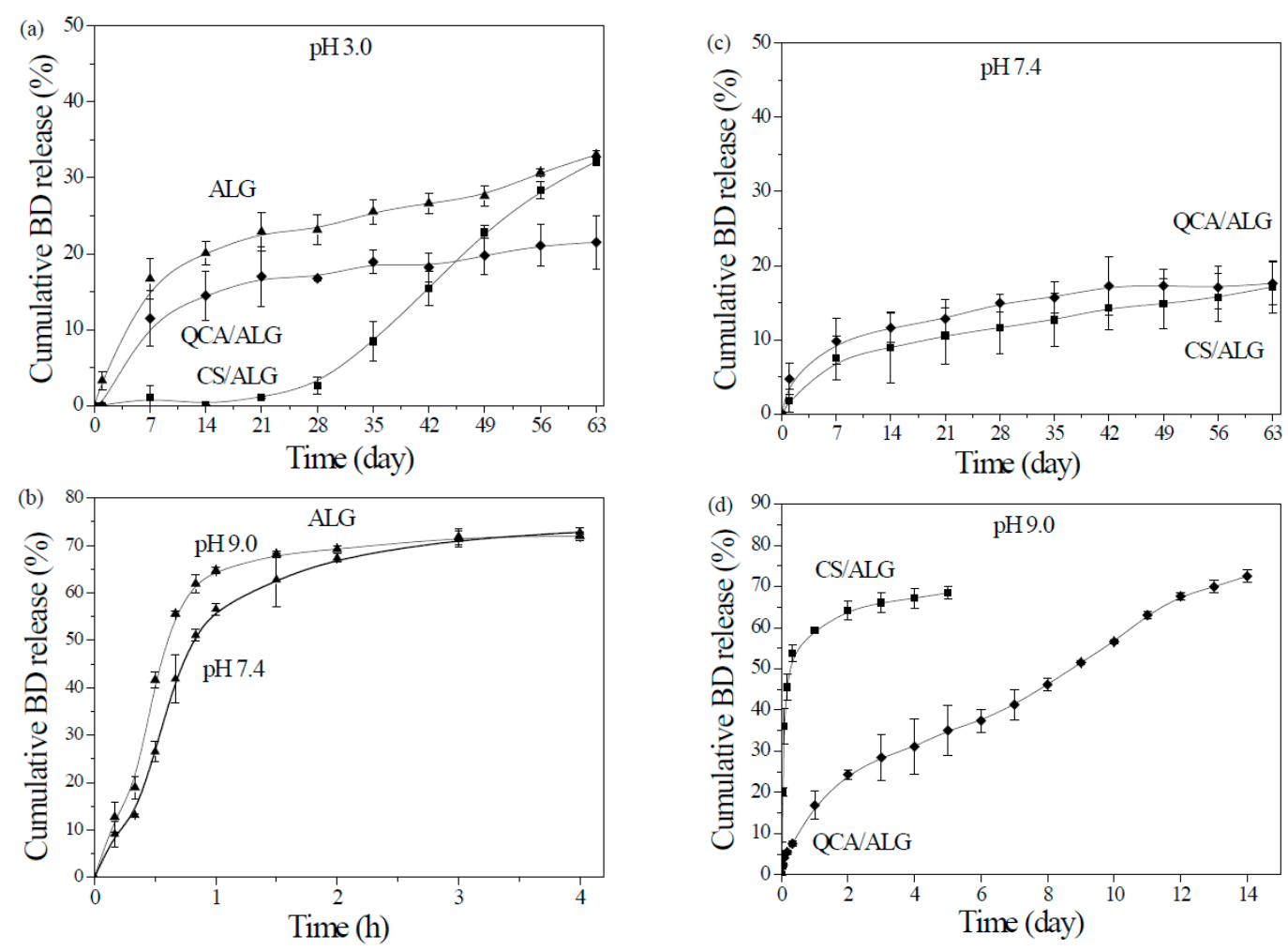

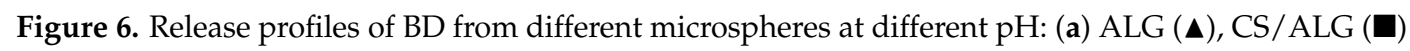

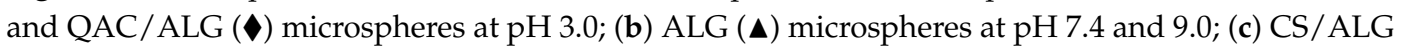
$(\boldsymbol{\square})$ and QAC/ALG $(\downarrow)$ microspheres at pH 7.4; and (d) CS/ALG (घ) and QAC/ALG ( $)$ microspheres at $\mathrm{pH} 9.0$.

Figure $6 \mathrm{~b}$ shows the release of $\mathrm{BD}$ at $37^{\circ} \mathrm{C}$ from ALG microspheres in PBS of $\mathrm{pH} 7.4$ and 9.0. A high burst release of around $56 \%$ and $65 \%$ was discovered for $\mathrm{pH} 7.4$ and 9.0, respectively, in the first hour, followed by a gradual release, reaching about $70 \%$ of the loaded amount after $4 \mathrm{~h}$. This result is similar to earlier work. Kim et al. showed that the release of BD from the ALG beads in water was rapid during the first hour, followed by a gradual release up to $3 \mathrm{~h}$ [32]. Baimark and Srisuwan prepared ALG microspheres by a water-in-oil emulsion solvent diffusion method [10]. The ALG microspheres were post-cross-linked with calcium ions. They also demonstrated that the release of BD 
from the ALG microspheres in PBS of $\mathrm{pH} 7.4$ at $37^{\circ} \mathrm{C}$ was rapid during the first hour, followed by a gradual release up to $24 \mathrm{~h}$.

It was obvious that the cumulative BD release at $\mathrm{pH} 7.4$ and 9.0 was much higher than that pH 3.0, suggesting that calcium ion cross-linked ALG microspheres are not stable in neutral and basic environment. ALG microspheres are easily broken in PBS at $\mathrm{pH} 7.4$ because of ion exchange, and therefore their drug release rates are high [33]. ALG is protonated into the insoluble form of alginic acid at $\mathrm{pH}$ 3.0, since alginic acid has a pKa of 4.25 [34]. Therefore, ALG microspheres had a lower release rate at $\mathrm{pH}$ 3.0.

In contrast, ALG microspheres coated with CS and QCA resulted in a small burst release of 5\% and $2 \%$ in PBS of $\mathrm{pH} 7.4$, respectively, followed by a very slow release reaching $17 \%$ of the loaded amount after 63 days (Figure $6 c$ ). No significant difference in the degree of release between CS/ALG and QAC/ALG microspheres was founded $(p<0.05)$. The lower burst release and slower release rate indicated that the CS and QAC shells coated on the surface of ALG microspheres could effectively improve their stability at neutral environment, and thus effectively control the release of BD.

CS/ALG microspheres in PBS of pH 9.0 showed a high burst release of around $54 \%$ in first $8 \mathrm{~h}$ followed by only an additional release of $14 \%$ over the next four days (Figure $6 \mathrm{~d}$ ). In contrast, no burst release was observed for QAC/ALG microspheres. The drug release was significantly prolonged to 14 days by the coating of QCA onto ALG microspheres as compared to ALG ( $4 \mathrm{~h}$ ) and CS/ALG microspheres (five days). Seventy-three percent of the loaded does was released from QAC/ALG microspheres after 14 days. The pKa of CS is approximately 6.5 [35]. Therefore, at $\mathrm{pH} 9.0$, the amino groups of CS were no longer significantly charged due to deprotonation, which weakens the extent of the electrostatic interaction with carboxyl groups of ALG. However, QAC still had permanent positively charged quaternary ammonium groups that interact strongly with ALG. Moreover, more amount of QAC was coated onto the surface of ALG microspheres compared with CS. Therefore, a slower release rate was observed for QAC/ALG microspheres. Although, compared to CS, QAC had no obvious effect in neutral environment, it did significantly affect the release of BD in basic environment.

\section{Conclusions}

In this investigation, quaternary ammonium monomers were graft co-polymerized onto CS using ammonium persulfate as a redox initiator. NMR and FTIR spectra confirmed the formation of graft co-polymer. The ALG, CS/ALG and QAC/ALG microspheres with narrow size distribution and regular spherical shape have been successfully fabrication. The in vitro release study showed that the release of $\mathrm{BD}$ from microspheres was $\mathrm{pH}$ dependent. Compared to ALG microspheres, QAC/ALG and CS/ALG microspheres could reduce the degree of burst release of BD in neutral and basic environment. Moreover, QAC/ALG microspheres showed prolonged release profiles in basic environment. According to the results of this study, the QAC/ALG microspheres have a potential as a carrier for the $\mathrm{pH}$-controlled release of water-soluble macromolecular drugs.

Acknowledgments: The authors wound like to thank the Ministry of Science and Technology of the Republic of China, Taiwan (contract No. MOST 103-2221-E-224-011 and MOST104-2815-C-224-0087-E) for financially supporting this research.

Author Contributions: Kuo-Yu Chen designed the experiments and wrote the paper. Si-Ying Zeng analyzed the data.

Conflicts of Interest: The authors declare no conflict of interest.

\section{References}

1. Rizwan, M.; Yahya, R.; Hassan, A.; Yar, M.; Azzahari, A.D.; Selvanathan, V.; Sonsudin, F.; Abouloula, C.N. $\mathrm{pH}$ Sensitive hydrogels in drug delivery: Brief history, properties, swelling, and release mechanism, material selection and applications. Polymers 2017, 9, 137. [CrossRef] 
2. Martín, M.J.; Calpena, A.C.; Fernández, F.; Mallandrich, M.; Gálvez, P.; Clares, B. Development of alginate microspheres as nystatin carriers for oral mucosa drug delivery. Carbohydr. Polym. 2015, 117, 140-149. [CrossRef] [PubMed]

3. Omer, A.M.; Tamer, T.M.; Hassan, M.A.; Rychter, P.; Mohy Eldin, M.S.; Koseva, N. Development of amphoteric alginate/aminated chitosan coated microbeads for oral protein delivery. Int. J. Biol. Macromol. 2016, 92, 362-370. [CrossRef] [PubMed]

4. Suksamran, T.; Ngawhirunpat, T.; Rojanarata, T.; Sajomsang, W.; Pitaksuteepong, T.; Opanasopit, P. Methylated $N$-(4-N,N-dimethylaminocinnamyl) chitosan-coated electrospray OVA-loaded microparticles for oral vaccination. Int. J. Pharm. 2013, 448, 19-27. [CrossRef] [PubMed]

5. Saludas, L.; Pascual-Gil, S.; Prósper, F.; Garbayo, E.; Blanco-Prieto, M. Hydrogel based approaches for cardiac tissue engineering. Int. J. Pharm. 2017, 523, 454-475. [CrossRef] [PubMed]

6. Chang, B.; Ahuja, N.; Ma, C.; Liu, X. Injectable scaffolds: Preparation and application in dental and craniofacial regeneration. Mater. Sci. Eng. R 2017, 111, 1-26. [CrossRef]

7. Deng, K.L.; Zhong, H.B.; Tian, T.; Gou, Y.B.; Li, Q.; Dong, L.R. Drug release behavior of a pH/temperature sensitive calcium alginate/poly( $N$-acryloylglycine) bead with core-shelled structure. Express Polym. Lett. 2010, 4, 773-780. [CrossRef]

8. Krishna Rao, K.S.V.; Ha, C.S. pH Sensitive hydrogels based on acryl amides and their swelling and diffusion characteristics with drug delivery behavior. Polym. Bull. 2009, 62, 167-181. [CrossRef]

9. Lee, K.Y.; Mooney, D.J. Alginate: Properties and biomedical applications. Prog. Polym. Sci. 2012, 37, $106-126$. [CrossRef] [PubMed]

10. Baimark, Y.; Srisuwan, Y. Preparation of alginate microspheres by water-in-oil emulsion method for drug delivery: Effect of $\mathrm{Ca}^{2+}$ post-cross-linking. Adv. Powder Technol. 2014, 25, 1541-1546. [CrossRef]

11. Moya, M.L.; Morley, M.; Khanna, O.; Opara, E.C.; Brey, E.M. Stability of alginate microbead properties in vitro. J. Mater. Sci. Mater. Med. 2012, 23, 903-912. [CrossRef] [PubMed]

12. Anal, A.K.; Bhopatkar, D.; Tokura, S.; Tamura, H.; Stevens, W.F. Chitosan-alginate multilayer beads for gastric passage and controlled intestinal release of protein. Drug Dev. Ind. Pharm. 2003, 29, 713-724. [CrossRef] [PubMed]

13. Peng, Z.X.; Wang, L.; Du, L.; Guo, S.R.; Wang, X.Q.; Tang, T.T. Adjustment of the antibacterial activity and biocompatibility of hydroxypropyltrimethyl ammonium chloride chitosan by varying the degree of substitution of quaternary ammonium. Carbohydr. Polym. 2010, 81, 275-283. [CrossRef]

14. He, M.; Chu, C.H. Dual stimuli responsive glycidyl methacrylate chitosan-quaternary ammonium hybrid hydrogel and its bovine serum albumin release. J. Appl. Polym. Sci. 2013, 130, 3736-3745. [CrossRef]

15. Shi, X.W.; Du, Y.M.; Li, J.; Su, X.L.; Yang, J.H. Release characteristics of brilliant blue from calcium-alginate beads coated with quaternized chitosan. J. Microencapsul. 2006, 23, 405-415. [CrossRef] [PubMed]

16. Hassan, M.M. Binding of a quaternary ammonium polymer-grafted-chitosan onto a chemically modified wool fabric surface: Assessment of mechanical, antibacterial and antifungal properties. RSC Adv. 2015, 5, 35497-35505. [CrossRef]

17. Viet, D.; Beck-Candanedo, S.; Gray, D.G. Synthesis and characterization of blue dextrans. Carbohydr. Polym. 2008, 74, 372-378.

18. Sriamornsak, P.; Kennedy, R.A. Effect of sodium fluorescein on release characteristics of a macromolecule from calcium alginate beads. Carbohydr. Polym. 2011, 84, 1208-1212. [CrossRef]

19. Endo, K.; Anada, T.; Yamada, M.; Seki, M.; Sasaki, K.; Suzuki, O. Enhancement of osteoblastic differentiation in alginate gel beads with bioactive octacalcium phosphate particles. Biomed. Mater. 2015, 10, 065019. [CrossRef] [PubMed]

20. Sobol, M.; Bartkowiak, A.; de Haan, B.; de Vos, P. Cytotoxicity study of novel water-soluble chitosan derivatives applied as membrane material of alginate microcapsules. J. Biomed. Mater. Res. Part A 2013, 101, 1907-1914. [CrossRef]

21. Song, H. Synthesis and application of cationic starch graft polymer by using the complex initiation system. Carbohydr. Polym. 2010, 82, 768-771. [CrossRef]

22. Igberase, E.; Osifo, P.; Ofomaja, A. The adsorption of copper (II) ions by polyaniline graft chitosan beads from aqueous solution: Equilibrium, kinetic and desorption studies. J. Environ. Chem. Eng. 2014, 2, 362-369. [CrossRef] 
23. Liu, W.; Huang, Y.; Liu, H.; Hu, Y. Composite structure of temperature sensitive chitosan microgel and anomalous behavior in alcohol solutions. J. Colloid Interface Sci. 2007, 313, 117-121. [CrossRef] [PubMed]

24. Wang, W.L.; Yu, W.D. Preparation and characterization of CS-g-PNIPAAm microgels and application in a water vapour-permeable fabric. Carbohydr. Polym. 2015, 127, 11-18. [CrossRef] [PubMed]

25. Umar, A.; Abu Naim, A.; Sanagi, M.M. Synthesis and characterization of chitosan grafted with polystyrene using ammonium persulfate initiator. Mater. Lett. 2014, 124, 12-14. [CrossRef]

26. Lim, S.H.; Hudson, S.M. Synthesis and antimicrobial activity of a water-soluble chitosan derivative with a fiber-reactive group. Carbohydr. Res. 2004, 339, 313-319. [CrossRef] [PubMed]

27. Rivas, B.L.; del Carmen Aguirre, M.; Pereira, E.; Moutet, J.C.; Aman, E.S. Capability of cationic water-soluble polymers in conjunction with ultrafiltration membranes to remove arsenate ions. Polym. Eng. Sci. 2007, 47, 1256-1261. [CrossRef]

28. Sashiwa, H.; Yamamori, N.; Ichinose, Y.; Sunamoto, J.; Aiba, S. Michael reaction of chitosan with various acryl reagents in water. Biomacromolecules 2003, 4, 1250-1254. [CrossRef] [PubMed]

29. Ji, Y.L.; An, Q.F.; Zhao, F.Y.; Gao, C.J. Fabrication of chitosan/PDMCHEA blend positively charged membranes with improved mechanical properties and high nanofiltration performances. Desalination 2015, 357, 8-15. [CrossRef]

30. Hu, H.; Yu, L.; Tan, S.; Tu, K.; Wang, L.Q. Novel complex hydrogels based on N-carboxyethyl chitosan and quaternized chitosan and their controlled in vitro protein release property. Carbohydr. Res. 2010, 345, 462-468.

31. Li, Z.; Yang, F.; Yang, R. Synthesis and characterization of chitosan derivatives with dual-antibacterial functional groups. Int. J. Biol. Macromol. 2015, 75, 378-387. [CrossRef] [PubMed]

32. Kim, M.H.; Kim, J.C.; Lee, H.Y.; Kim, J.D.; Yang, J.H. Release property of temperature-sensitive alginate beads containing poly(N-isopropylacrylamide). Colloids Surf. B. Biointerfaces 2005, 46, 57-61. [CrossRef] [PubMed]

33. Sun, X.; Shi, J.; Xu, X.; Cao, S. Chitosan coated alginate/poly(N-isopropylacrylamide) beads for dual responsive drug delivery. Int. J. Biol. Macromol. 2013, 59, 273-281. [CrossRef] [PubMed]

34. Wyss, A.; von Stockar, U.; Marison, I.W. Production and characterization of liquid-core capsules made from cross-linked acrylamide copolymers for biotechnological applications. Biotechnol. Bioeng. 2004, 86, 563-572. [CrossRef] [PubMed]

35. Dehousse, V.; Garbacki, N.; Colige, A.; Evrard, B. Development of pH-responsive nanocarriers using trimethylchitosans and methacrylic acid copolymer for siRNA delivery. Biomaterials 2010, 31, 1839-1849. [CrossRef] [PubMed]

(C) 2017 by the authors. Licensee MDPI, Basel, Switzerland. This article is an open access article distributed under the terms and conditions of the Creative Commons Attribution (CC BY) license (http:/ / creativecommons.org/licenses/by/4.0/). 